\title{
Correspondence
}

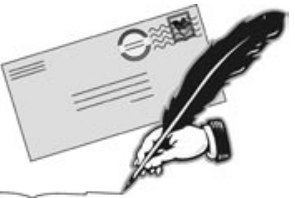

\section{A new technique for midline orotracheal tube fixation}

To the Editor:

Airway problems in children with cleft lip and palate have been recognized for more than 70 years. ${ }^{1}$ Contrary to the standard practice of fixing the endotracheal tube (ETT) at the angle of the mouth, fixation of the ETT, in the midline, for better preservation of anatomical landmarks, is desirable in these settings. The chances of life threatening complications, including accidental extubation, endobronchial intubation, and kinking, are increased whenever the ETT is fixed in the midline.

We describe, herein, a simple device for ETT fixation in the midline, following oral intubation in patients undergoing cleft lip and palate surgery. The device is made of a polyvinyl chloride (PVC) sheet. It is pentagonally shaped, with a hole in the upper margin of the midline intended as passage for an ETT of $5 \mathrm{~mm}$ internal diameter (Figure 1). To further enhance ETT fixation, another six, smaller holes are located at the margin of the PVC sheet for passage of thread (Figure $1)$. Once the orotracheal intubation is performed, the PVC device is advanced over the proximal end of the ETT through the larger midline hole. Next, a double loop of thread (already passed into the smaller holes) is looped over the ETT. Lastly, the ends of the thread are pulled apart, so as to provide a firm grip on the ETT. The components of the whole assembly (ETT, device, and thread) are fixed to each other, as well as to the surrounding skin, with the use of adhesive plaster (Figure 2).

We have used this device on twenty-six, consecutive, pediatric patients undergoing cleft lip repair, without any incidence of accidental extubation, endobronchial intubation, or kinking. The wide base of the PVC device helps to provide better stability and fixation of the ETT. The margin of the hole in the PVC device provides support to the ETT and reduces the likelihood of migration in either direction. In conclusion, this technique is simple, inexpensive, safe, easy to perform, and does not hinder the application of retractors required to conduct the surgical procedure.

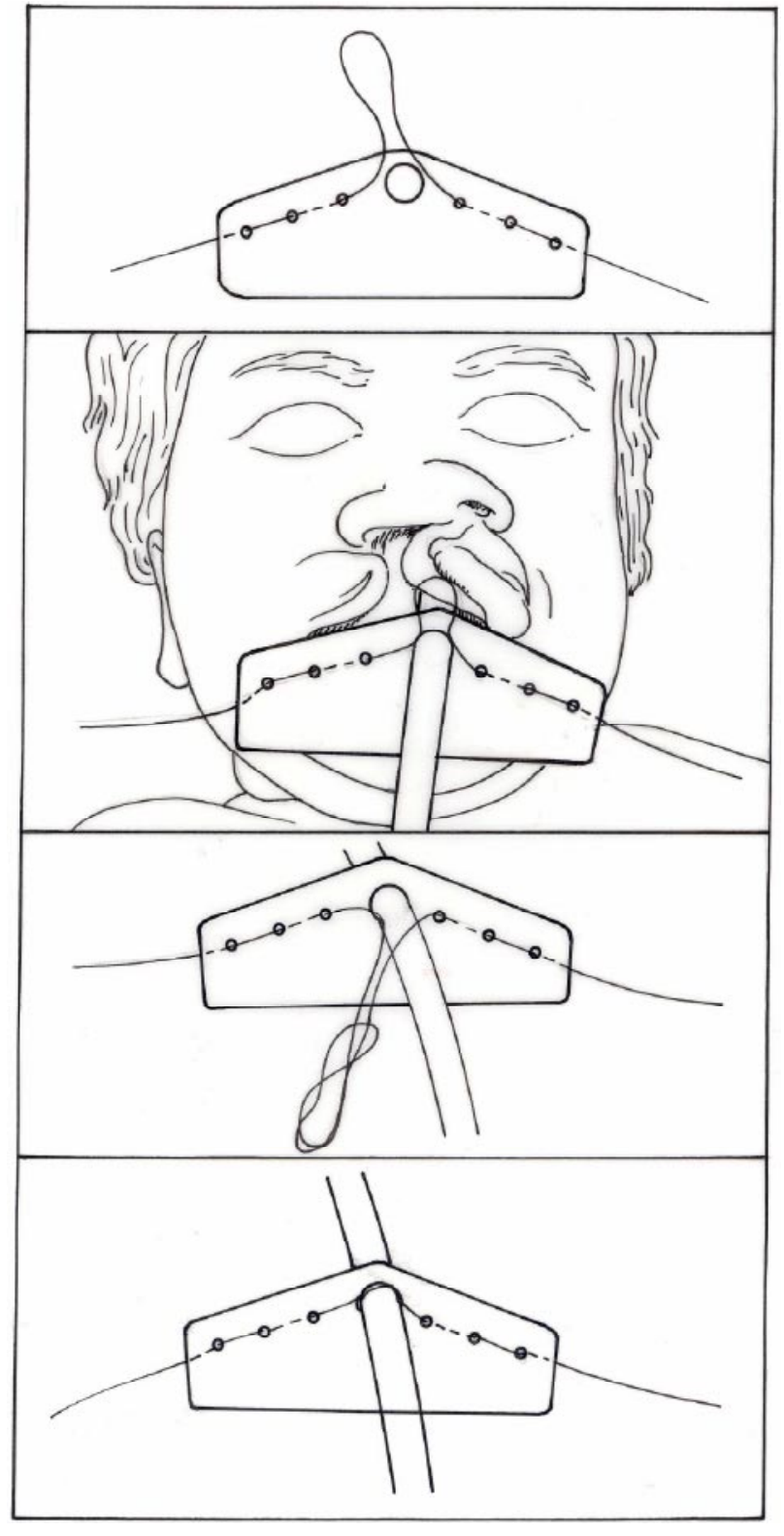

FIGURE I Diagrammatic representation of the endotracheal tube (ETT) fixation device, following oral intubation, and the technique of ETT fixation in the midline. 


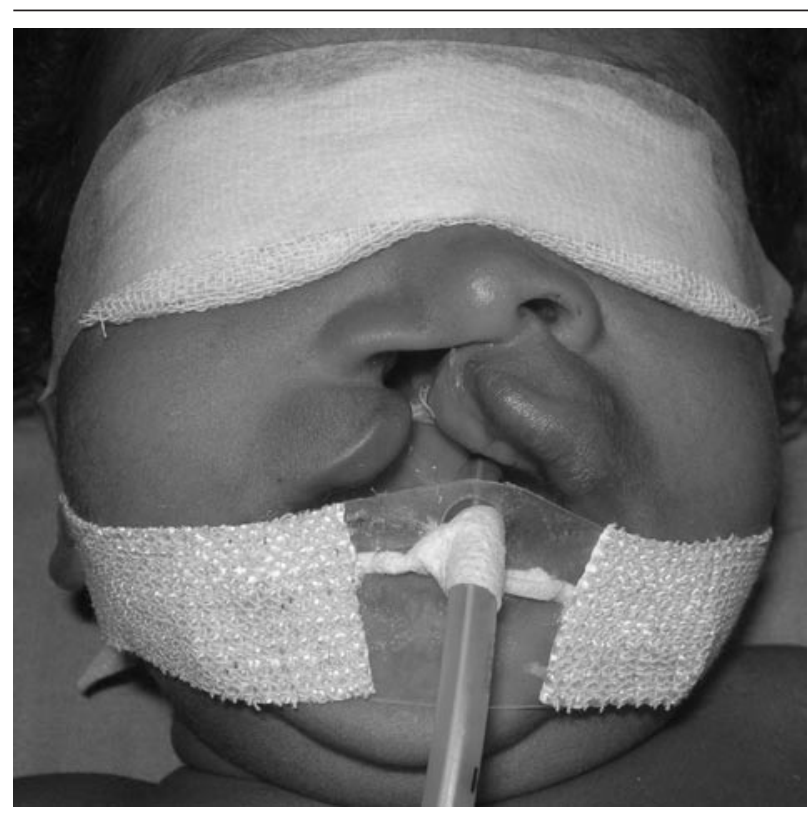

FIGURE 2 A combined cleft lip and cleft palate in a patient with an oral endotracheal tube (ETT), in situ, fixed firmly in the midline with the help of the ETT fixation device.

Sishir Agarwal MD

Devendra Gupta MD

Anil Agarwal MD

Sanjay Gandhi Postgraduate Institute of Medical

Sciences, Lucknow, India

Source of financial support: None.

E-mail: aagarwal@sgpgi.ac.in

Accepted for publication March 12, 2008.

\section{Reference}

1 Hatch DJ. Magill's endotracheal catheter device for use during repair of cleft lip and palate. Paediatr Anaesth 1995; 5: 199-201.

\section{Hemoglobin $M$ variant and congenital methemoglobinemia: methylene blue will not be effective in the presence of bemoglobin $M$}

To the Editor:

We thank Drs Melarkode and Prinzhausen for their description of the anesthetic management of an asymptomatic patient with congenital methemoglobinemia due to hemoglobin $\mathrm{M}(\mathrm{HbM}) .^{1}$ The practical difficulty in management is that such a patient will remain cyanosed with an erroneously low reading on the pulse oximeter. ${ }^{2}$ Serial blood gases are reassuring, but continuous monitoring of oxygenation is lost. We also were faced with a 44-yr-old patient with congenital HbM (subtype 1 WATE) for major maxillofacial reconstructive surgery with vascular free flap, who would require postoperative intensive care. He was similarly asymptomatic, because only $9 \%$ of his hemoglobin was $\mathrm{HbM}$. He was cyanosed with a reading of $40 \%$ on the pulse oximeter and a $\mathrm{PO}_{2}$ of 109.5 $\mathrm{mmHg}$ on room air.

Searching for alternative means of monitoring perioperatively, we considered using continuous transcutaneous oxygen tension monitoring $\left(\mathrm{pTcO}_{2}\right)$. Continuous transcutaneous oxygen tension monitoring is established in neonatal intensive care ${ }^{3}$ to monitor premature babies, in whom pulse oximetry has its limitations. ${ }^{4}$ This is a Clark type electrode applied to the skin and heated. Vasodilation induced by the heat allows correlation between arterial $\mathrm{PO}_{2}$ and skin $\mathrm{PO}_{2}{ }^{5}$ A preoperative check on the function of the monitor on the patient was encouraging and we found that increasing and decreasing the $\mathrm{F}_{1} \mathrm{O}_{2}$ had the anticipated effect on the reading of $\mathrm{pTcO}_{2}$.

We decided to use the $\mathrm{pTcO}_{2}$ monitor intraoperatively, along with regular arterial blood gas samples during the 12-hr case. The $\mathrm{pTcO}_{2}$ monitor helped us to continuously monitor the patient's oxygenation. Encouraged by performance of the monitor, it was subsequently used throughout the postoperative period, in intensive care, and on the ward.

Disadvantages of $\mathrm{pTcO}_{2}$ include the fact that the sensor is heated to $44^{\circ} \mathrm{C}$, and therefore its site must be changed every four hours to prevent heat damage to the skin. Also, for the first ten to $20 \mathrm{~min}$ after each site change, the reading is inaccurate while the sensor equilibrates with the skin. Also there is a one-minute lag time between changes in arterial $\mathrm{PO}_{2}$ and $\mathrm{pTcO}_{2}$ which would be disadvantageous in a crisis. We prevented possible interference in the function of the sensor with nitrous oxide,${ }^{6}$ by using oxygen in air.

We found the transcutaneous oxygen tension monitor invaluable for our patient. We recommend its use in other patients in whom the pulse oximeter cannot be used reliably, such as the case described by Drs Melarkode and Prinzehausen.

Frances Spears FRCA

Arnab Banerjee FRCA

Luton and Dunstable Hospital NHS Trust, Luton, United Kingdom

E-mail: Francesspears@aol.com

Accepted for publication March 25, 2008. 